\title{
Artificial milk-feeding women's views of their feeding choice in Ireland
}

\author{
Margaret Carroll, RM, MSc (Associate Professor in Midwifery) ${ }^{a, *}$, Louise Gallagher, \\ RM, MSc, PhD (Assistant Professor in Midwifery)a , Mike Clarke, BA, DPhil (Chair of \\ Research Methodology and Director of the All-Ireland Hub for Trials Methodology \\ Research) $)^{\mathrm{b}}$, Sally Millar, RM, MSc (Assistant Professor in Midwifery) ${ }^{\mathrm{a}}$, Cecily Begley, \\ RM, MSc, PhD, FTCD (Chair of Nursing and Midwifery) ${ }^{a}$ \\ a Trinity College Dublin, Dublin 2, Ireland \\ b The Queen's University of Belfast, Northern Ireland, UK
}

\section{A R T I C L E I N F O}

Article history:

Received 14 May 2014

Received in revised form

20 February 2015

Accepted 2 March 2015

Keywords:

Artificial milk feeding

Bottle feeding

Infant feeding choice

Women's views

\begin{abstract}
A B S T R A C T
Objective: despite the well-documented benefits of breast feeding to both mother and child, breastfeeding initiation rates in Ireland are the second lowest in Europe. This study set out to explore the views of women from low socio-economic groups in Ireland on their choice to feed their infants artificial milk, and to elicit factors that may encourage these women to breast feed in the future.

Design: a qualitative descriptive approach was used.

Methods: data were collected through recorded focus groups and individual interviews, using a semistructured interview schedule. Data were transcribed verbatim.

Setting: interviews took place in two regions in the Republic of Ireland, north and south.

Participants: a purposive sample was drawn from the population of 2572 women taking part in the Irish Infant Feeding Study who had never breast fed previously, had intended to, and had, fed this infant artificial milk and who had completed their education before they were 18 years of age. Two focus groups with two women in each were conducted and six women took part in individual interviews.

Analysis: constant comparative analysis was performed to construct the categories and concepts that led to the final themes.

Findings: these artificial milk-feeding women based their infant feeding decision on many social and experiential factors. The major influences on their decisions were: personal attitudes toward feeding methods, and external influences on infant feeding methods. Attitudes towards other women and feeding future infants reinforced a strong preference towards artificial milk feeding.

Key conclusions and implications for practice: it is apparent that a prevailing culture that is unreceptive to breast feeding and the lack of positive breast-feeding role models, contributed to a strong commitment to artificial milk feeding for these participants. Promotion of breast feeding must take account of the complex contexts in which women make decisions. Advice regarding breast feeding should take account of women's feelings and avoid undue pressure, while still promoting the benefits of breast feeding to women and their families.
\end{abstract}

(c) 2015 Elsevier Ltd. All rights reserved.

\section{Introduction}

Breast feeding has consistently been shown to reduce mortality among preterm infants (Lucas and Cole, 1990; Lucas et al., 1998; Vohr et al., 2006) and may offer some protection against the development of early onset insulin dependent diabetes mellitus (Virtanen et al., 1991), type 2 diabetes (Owen et al., 2006), raised

\footnotetext{
* Correspondence to: Trinity College Dublin, 24 D’Olier St, Dublin 2, Ireland.

E-mail addresses: carrolol@tcd.ie (M. Carroll), mclarke@qub.ac.uk (M. Clarke), cbegley@tcd.ie (C. Begley).
}

adult blood pressure (Singhal et al., 2001) and obesity (Fewtrell, 2004; Harder et al., 2005). For women, breast feeding leads to a lower incidence of premenopausal breast cancer (Enger et al., 1997; Beral et al., 2002), ovarian cancer (Rosenblatt and Thomas, 1993) and osteoporosis (Cummings and Klineberg, 1993), and a faster return to pre-pregnancy weight (Dewey et al., 1995).

Despite these well-proven benefits, rates of breast-feeding initiation in Ireland in 1992 were the lowest in Europe (Freeman, 1996). Perinatal statistics show a recent increasing trend in breastfeeding rate from 36\% in 1999 to $45.9 \%$ in 2010 (ESRI, 2013), still the second lowest rate in Europe. 
Factors known to affect breast-feeding rates internationally include socio-economic status, age and education level (Dyson et al., 2005; Gudnadottir et al., 2006). The Infant Feeding Survey conducted in the United Kingdom (UK) in 2010 showed that women who left full time education aged 16 years or younger were among those least likely to breast feed (McAndrew et al., 2012), a finding consistent with Irish studies since the early 1980s (McSweeney and Kevany, 1982; Fitzpatrick et al., 1994; Greally, 1997; McDermott and O’Neill, 2000; Tarrant, 2008). A longitudinal survey of 2223 infants in Canada found that, when other confounding variables were accounted for, women who had a high school diploma were five times more likely to initiate breast feeding (Dubois and Girard, 2003). The influence of demographic variables on breast-feeding trends has proved challenging to its promotion in Ireland and other countries, as these are frequently not amenable to interventions and require wider societal changes (Amir and Donath, 2008). It has been reported that in the UK, breast feeding is a major factor in inequalities in health (Oakley et al., 2013) and this is a situation that is likely to be replicated in Ireland (Tarrant et al., 2013). Hence, not being breast fed is both a cause and a consequence of social inequalities. Improving breast-feeding rates in the Ireland has been a focus of successive governments over the last decade (DoH\&C, 2005).

In 2008-2011, a national study of infant feeding was undertaken in Ireland $(n=2527)$. Questionnaires were completed at three time-points: within two days of birth, at three to four months and six to seven months. In the questionnaire completed within two days of birth, 854 respondents (34\%) stated that they had intended to artificial milk feed. At three to four months, the majority of infants born in Ireland were being fully fed artificial milk (72\%, $n=1077)$ (Present Authors, 2010), and the women who were least likely to breast feed were Irish women classified as having lower socio-economic status. In order to discover why this cohort of women chose to feed artificial milk, an explorative study was conducted.

Aim

The aims of this study were to explore the views of women from low socio-economic groups in Ireland on their choice to feed their infants artificial milk and to elicit factors that may encourage these women to breast feed in the future.

\section{Methods}

A qualitative descriptive approach was used, involving focus group and individual interviews. Ethical approval for the study was given by the Research Ethics Committee of the Faculty of Health Sciences, Trinity College Dublin, and all women gave informed consent to take part.

The population for the main Irish Infant Feeding Study included all women who gave birth to live babies ( 24 weeks gestation or greater) in one of the 20 maternity hospitals/units (or under the care of the 19 independent midwives) in the Republic of Ireland during the month of April 2008. Women who gave birth to a stillborn baby or whose baby died within the first 48 hours during the study period were excluded. The study took place over three time periods. In Phase 1, 2527 women took part, which represents a 33\% response rate for all births in the month of April 2009. Phase 2 (two to three months postnatal) consisted of a postal survey of all women who completed Phase 1 of this study, of whom 72\% (1826) responded. A postal survey was also employed during Phase 3 (six to seven months postnatal), for those women ( $n=621$ ) who indicated that they were breast feeding when they completed Phase 2 .

\section{Sample selection}

The sample for this study was drawn from the population of women in Phase 2 of the Irish Infant Feeding Study (Present Authors, 2010) who had intended to, and did, artificial milk feed $(n=583)$. As Ireland does not currently utilise any deprivation scoring system, socio-economic status was determined based on the women's occupation, which had been adopted in the 2006 census enquiry (CSO, 2007).

\section{Sample size}

It was planned to hold six focus groups with five to nine participants in each. The inclusion criteria for these focus groups were women who had never breast fed a previous child, had intended to, and had, fed this infant artificial milk and who had completed their education before they were 18 years of age or had an occupation classified as semi-skilled or unskilled. Invitations were sent to all women who met the selection criteria and had indicated in the Phase 2 questionnaire that they would be willing to participate in this part of the study. An information leaflet and consent form were circulated and, for convenience, focus groups were organised at centres geographically close to participants. Follow-up phones calls were made one week after posting the information leaflet.

The first focus group was held in the Midlands region of Ireland and 18 women were invited. A selection of times convenient to the participants were offered and travelling expenses provided; however, only two women were able to attend. Similar problems with a focus group in the southern region resulted in only two attendees out of 12 invited. As it was proving too difficult for these women, all of whom had at least one baby aged four to five months, and often other children as well, the remainder of the qualitative data were collected via telephone interviews. Women who had agreed to participate were notified of this change and 10 consented to be interviewed by telephone; however, data collection ceased after six telephone interviews, when no new substantive themes were emerging.

\section{Data collection}

A semi-structured interview schedule was developed from the literature and findings from Phase 2, to explore participants' views of the perceived barriers dissuading them from breast feeding and factors that might encourage breast feeding (Box 1). One team member (LG) acted as facilitator for all small focus groups and conducted all telephone interviews to ensure consistency. A second team member attended each small focus group to assist (MCa, SM), and take notes on group dynamics, which were incorporated in the findings.

Discussion and interaction between the two women in the small focus groups meant that the duration of these was longer

\section{Box 1-Semi-structured interview schedule (Focus Groups)}

- When did you decide how you would feed your baby?

- What was the most important thing for you when deciding how to feed your baby?

- Did anyone else influence how you fed your baby?

- How do you feel about breast feeding?

- Did anybody discuss breast feeding with you while you were pregnant with this baby?

- Is there anything that would have influenced you to breast feed your baby? 
(42 and 68 minutes), than the telephone interviews (between 10 and 16 minutes). However, it was evident from the views and description presented often in a relatively short space of time, that they both provided a rich source of data. All interviews were recorded and transcribed verbatim, using pseudonyms.

\section{Data analysis}

Thematic analysis took place through reading and rereading of the transcribed data, coding, categorisation and development of themes. The themes were then grouped into dimensions and perspectives, providing in-depth knowledge to the area of interest. Constant comparative analysis was performed to construct the categories and concepts, and theoretical sampling of women was undertaken in the telephone interviews as the core categories emerged. For example, when the needs of other children were identified as a theme, more multiparous women were sampled. Prolonged engagement with the data and the subject was undertaken and women's own words were used to improve credibility. A systematic process of maintaining an audit trail in terms of sequencing, recording, analysing and reporting data was also maintained. As women had already invested a significant amount of time in completing an earlier survey and participation in a small focus group or telephone interview, data were not returned to them for validation. As qualitative themes emerged, these were checked by two other members of the research team (SM, CB) for validation and confirmation. Recruitment ceased after 10 women had been interviewed as data saturation was judged to have occurred.

\section{Findings}

Ten women participated in the qualitative part of the study, all either married or living with partners. Two women had given birth to their first baby and the remainder had between two and seven children.

Three major themes emerged from the focus groups and interviews, suggesting that the major influences on infant feeding for these women are 'personal attitudes toward feeding methods,' 'external influences on infant feeding methods' and 'future attitudes toward infant feeding.' Within these themes, 13 subthemes were used to provide a summary of the findings.

\section{Personal attitudes toward feeding methods}

\section{'Breast feeding is not for me'}

Artificial milk-feeding women who agreed to take part in the focus groups and interviews had very definite views about their choice of feeding and most suggested that breast feeding was simply not for them:

It was never, yeah, it was never, breast feeding is just not for me. (Maura)

I mean, I just couldn't imagine doing it, I would listen to advice but I was not changeable. Yeah, really, breast feeding was never an issue. (Susan)

While it was apparent that some women in our study made decisions about infant feeding outside of the context of engagement with maternity services, often before they were pregnant, others indicated that they had not thought about infant feeding before confirmation of their pregnancy:

As soon as I found out I was pregnant I decided. Hadn't given it any thought before that really, but I think it was bottles all along for me. (Jackie)
Most women were clear to point out that they were not against breast feeding for other women and felt it was the 'right' thing to do:

I am happy to see others breast feeding. It's the most natural thing in the world. (Cathy)

\section{'Commitment to choices'}

Women talked about the strength of their feelings about deciding to feed artificial milk and suggested that this was important to them, and to other women. It was apparent that they felt that this was shared equally among breast and artificial milk-feeding women:

When a mother gets it into her head that...she's going to breast feed, I got it into my head I didn't want to breast feed; there was no persuading me at all. (Cathy)

Women had developed strategies to disengage from health professionals and friends when they talked to them about breast feeding:

By the fifth time (antenatal visit) I pretended to be considering breast feeding to stop the conversation. (Rosie)

I used to tell Sandra (friend who had breast fed) that I was thinking about doing it, just to shut her up, but I wasn't going to. (Susan)

\section{'Bottle feeding is just as good'}

Although almost all the women talked about the notion that breast was best, it was clear from their views and experiences that they believed artificial milk feeding was just as good for their baby, and some went to great lengths to justify their decision to feed artificial milk:

I know all there is to know about you know the extra benefits the baby gets and the whole lot from the mother's milk and all that, I mean I've seen...my first son and he thrived [on formula] and he still is a very strong and healthy little boy and now at this stage he's one and I mean he's just a really Billy Butcher of a child. (Maura)

I probably should have breast fed but the bottle was probably the better answer because I had 3 big babies and they were all hungry. I mean they are healthy-looking and they gained weight...so I don't think breast is best, to me it isn't...I think bottle is just as good. (Rosie)

\section{'It's easier to bottle feed'}

These women undoubtedly considered artificial milk feeding to be easier and less restrictive than breast feeding, and commented that this was a very important factor when choosing how to feed their baby. Women also spoke of how exhausting breast feeding was:

Bottle feeding is just easier... bottles are handy...you are not as tied to the baby. I don't mean I'd want to leave the baby every hour of the day but it means somebody can baby-sit for you, you know, partners can get up in the middle of the night and do a feed, to me it's easier. (Orla)

I think that the woman has gone basically through enough and that if she can have a little rest and her partner can actually feed the baby, instead of breast feeding yourself, it's making you twice as...tired than you already are anyway. (Sonia)

It just takes a lot more out of your body and you are already wrecked enough for the first few weeks (after birth). (Jackie) 
Some women commented that the needs of their other children were an important factor in choosing artificial milk feeding:

If you have other children, it's very demanding and draining on you as it is, so I think breast feeding would just... be too much work. (Avril)

'Physical aspect of breast feeding'

An important issue for many of the women was the physical notion of breast feeding:

I would have loved to have wanted to do it. I just never felt comfortable with anything on my breast, man or child (laughing). It does nothing for me. (Jackie)

Postnatal breast tenderness had been a reinforcing factor for some women in choosing to feed artificial milk:

It's just something I can't, I know how much pain I was in on my first one, my breasts were more sore than anything else and I thought I would never have a baby breast feeding because it was too painful. That was without even breast feeding. (Beth) Honestly, I think breast feeding is uncomfortable in every way and I really think that it's pointless. (Susan)

'Importance of personal history and memories of breast feeding'

The survey results (Present Authors, 2010) had highlighted that how the woman was fed herself and the behaviour and attitudes of her peers were influential in infant feeding decisions. Therefore, we asked participants to discuss whether they had any experience of breast feeding among family and friends. Although many of the women knew someone who had breast fed, several could not recall having ever seen a baby breast feeding:

I don't know anyone who has breast fed except for (partner's) mother, I wouldn't have seen anyone do it. That sounds mad doesn't it? (Susan)

Anybody I ever remember feeding their babies it's always been with bottles. (Jackie)

Some of the women talked about particular incidents relating to breast feeding or recounted stories that they felt might have influenced them in artificial milk feeding:

I remember when I was small my aunt came from America and we went out for the day and she started breast feeding a toddler in public; I was a small child but I still remember it, I nearly died, I was mortified (laughing). (Aine)

\section{External influences on infant feeding}

\section{'Family influences'}

Previous exposure to breast feeding among family and friends was a deterrent for some women. However, other women commented that they had family members who would be supportive of breast feeding. In particular, having a sister who breast fed, and the context of her experience, was relevant:

I witnessed my sister trying to breast feed and I didn't like the way it was going and I just said, the bottles are easier. (Beth) I have a sister, she had a child just before me and she breast fed, and I thought 'no way', the child just kept screaming, she wasn't satisfied with the breast milk. (Sonia)

This was countered by positive family experiences from some of the women:

I have a sister-in-law that just had a baby and she breast fed and she thinks it's the best thing ever (Maura)
My mother was pro breast feeding, she breast fed us all but I don't remember it. There was no anti breast feeding from other family members either, they'd actually be into it. (Orla)

Mothers and mothers-in-law were seen as having an interest in infant feeding but messages they conveyed to the new mothers were seen as subtle rather than having a strong influence or opinion:

His (partner) mother asked me, she's probably the only one that asked me would I breast feed because she breast fed a couple of her children but I said 'no, I wouldn't feel comfortable with it' so that was the end of that then. (Rosie)

My own mother...she wouldn't have sat down and said 'now you know you have to do this and that' but... if I had said 'I'm going to bottle feed' she probably would have said 'oh, maybe that's a better idea, you know, it might be easier for you'. That's the sort of way, it wasn't that she influenced me in such a way but I just know what she'd have preferred. (Orla)

\section{'Partner influences'}

All 10 women felt that their partners had not influenced them in any way:

My husband didn't have any choice of decision and would have supported me whatever. (Jackie)

However, women perceived artificial milk feeding as a way of enabling bonding with the baby's father:

I wanted to make sure the father bonded with the child as well because I know if you breast feed the father doesn't bond as much. (Avril)

My other children were all bottle fed and he'd feel left out now I'd say 'cos he loves giving them their night feed when they are babies. (Rosie)

'Perceptions of the attitudes of health professionals'

During their pregnancies women had differing views about the promotion of breast feeding by health professionals. A common theme was the notion of the 'pushy' midwife:

In the hospital on my first child (he's 11 now), the midwives came around and they wanted everybody to breast feed but I felt a bit under pressure to do it and I wasn't comfortable doing it. If anything, they probably persuaded me to bottle feed more than breast feeding, I think. (Jackie)

They (midwives) are very, very encouraging today for breast they push you a lot at the hospital visits. (Orla)

However, some women who had other children felt that health professionals did not try to encourage breast feeding if they had not breast fed before:

Nobody spoke about it this time. I suppose because it was my second child they didn't. They just took for granted that I'd be bottle feeding again. (Avril)

\section{'Cultural influences'}

Given the low incidence of breast feeding in Ireland, it is not surprising that women felt that artificial milk feeding was more culturally accepted in Ireland. They highlighted that previous and current generations had reinforced artificial milk feeding as the predominant method of feeding:

In Ireland it's more normal to bottle feed. (Jackie)

Breast feeding was not done in my generation, never, never, did I see anyone breast feeding when I was growing up. (Cathy) 
There is still a brigade out there who just think you shouldn't talk about it [breast feeding] at all. (Rosie)

\section{Future attitudes towards infant feeding}

\section{'Advice for other women'}

Women were keen to suggest that they would not deter other women from breast feeding, but their responses showed limited expectancy for the success of promotional activities:

I said you know 'try it see how you go, if it's for you well and good and if it's not don't be afraid to try a bottle.'...I'm not antibreast feeding in any way, I'm certainly not. (Sonia)

I'd tell other mums 'by all means give it a shot if you want to breast feed but there's no crime in giving bottles either. Do what suits you best'. (Rosie)

\section{'Views on breast-feeding promotion'}

Women were asked to reflect on breast-feeding promotion in Ireland and provided thoughts and strategies that were consistent with normalising breast feeding:

I think when they are having the antenatal classes beforehand, before you have the baby, that maybe if they brought a woman along who was prepared to breast feed in the class, I know it might sound a bit weird. (Jackie)

They could just maybe let other mothers see (a woman breast feeding) because when you say 'breast feed' to a young girl who is after giving birth to a baby, it's very strange and it's kind of a bit off-putting as well. If they've seen it beforehand, it mightn't be so scary for them. (Susan)

\section{'Nothing would persuade me'}

Despite offering strategies to encourage other women, almost all of the women suggested that this would not have influenced them, and gave a clear message that they were not amenable to the notion of breast feeding in the future:

I don't think anything would change my mind. (Avril)

I would never do it, not even if (baby) had been preterm. (Aine)

This finding demonstrates that artificial milk-feeding women are steadfast in their commitment to that method of feeding and present a challenging group in terms of the promotion and initiation of breast feeding. Only one of the participants suggested that she may be willing to breast feed in the future:

I mean, if I was to go and have another baby I wouldn't say I definitely wouldn't breast feed, I probably wouldn't, but I wouldn't say definitely not. (Susan)

\section{Discussion}

This qualitative component of the study of infant feeding in Ireland has been exploratory but its findings nevertheless suggest that women who feed artificial milk base their infant feeding decisions on many social and experiential factors. Many of the findings have been corroborated by previous research in contexts outside of the Republic of Ireland (Hoddinott and Pill, 1999; Stewart-Knox et al., 2003; Greene et al., 2003). For example, the finding that these women made decisions about infant feeding before any contact with maternity services, and often before they were pregnant, was consistent with results from other studies (Hoddinott and Pill, 1999; Earle, 2000). In line with the literature (Earle, 2000; Stewart-Knox et al., 2003; Brown et al., 2011) these women considered bottle feeding to be easier than breast feeding and commented that this was a very important factor when choosing how to feed their baby. Similarly, the notion they expressed that breast feeding restricted freedom had been noted previously (Stewart-Knox et al., 2003), as has their view that artificial milk feeding is just as good as breast feeding (Murphy 1999; Earle 2000). This suggests that artificial milk-feeding women are aware of the benefits of breast feeding and go to great lengths to justify their decision.

In contrast to earlier research (Greene et al., 2003; Tarrant, 2008), women did not explicitly highlight embarrassment as an influential factor. However, personal 'comfort' was described as important. A recent meta-synthesis of 14 qualitative studies exploring women's decision-making around infant feeding also found that a sense of personal comfort emerged as a key theme for women (Nelson, 2012). This finding is important in the context of breast feeding in societies where perceptions of motherhood may have been reconstructed (Avishai, 2007) and hence it warrants further investigation in Ireland and other countries where it has been reported (Nelson, 2012).

A non-breast-feeding culture pervaded among these women, who felt that artificial milk feeding was more culturally accepted in Ireland, similar to views expressed by mothers in the UK (Brown et al., 2011). Given the low incidence of breast feeding in Ireland, this is not surprising. The women were keen to suggest that they would not deter other women from breast feeding, but their responses showed limited expectancy for the success of promotional activities (Blyth et al., 2002). It is apparent that, in order to influence other women, promotion of breast feeding must normalise breast feeding in society. Limited exposure to breast feeding has previously been shown to have a negative influence on attitudes towards breast feeding (McFadden and Toole, 2006). In contrast, increased exposure to breast feeding correlates with increased initiation of breast feeding (Griffiths et al., 2005).

In common with breast-feeding women (Bailey et al., 2004), artificial milk-feeding women require positive breast-feeding role models (Stewart-Knox et al., 2003) in order to counter the apparent negative influences and discourses surrounding breast feeding. Surprisingly, women who breast feed also have some negative views of the experience, even when it has been successful (Forster and McLachlan, 2010).

It has been noted in previous research that the influence of different, informal support sources is likely to vary depending on the woman's own social and cultural context (McInnes and Chambers, 2008). However, as is demonstrated in this study, the strong influence of family and friends is particularly evident among women from lower socio-economic groups (Hoddinott and Pill, 1999; Khoury et al., 2005; McInnes and Chambers, 2008). Including partners in breast-feeding education may improve success (Mitchell-Box and Braun, 2012) as this study showed that they were virtually excluded from women's decisionmaking. However, in common with previous research (StewartKnox et al., 2003) all 10 women in this study felt that their partners had not influenced them in any way.

A Cochrane review of support interventions on breast-feeding initiation rates has also shown that health education and peer support interventions can result in some improvements in the number of women beginning to breast feed (Dyson et al., 2005). However, rapid wide-scale cultural changes to attitudes and behaviours associated with breast feeding are more difficult to achieve (Cattaneo et al., 2005). Health professionals need to include all women when promoting breast feeding and not make assumptions about women based on their previous infant feeding methods. However, many women in this study gave a clear message that they were not amenable to the notion of breast feeding in the future. It has been noted that promotion of breast feeding among women who did not breast feed their earlier children is likely to be difficult, as they display little motivation 
to breast feed (Janke, 1994) and usually have a staunch commitment to feed their infants artificial milk. Advice regarding breast feeding needs to take account of women's feelings and avoid undue pressure in order to be 'woman centred' and not 'breastfeeding centred' (Hoddinott and Pill, 2000), as imposing one's own values and beliefs on women can have moral and ethical repercussions (Ryan et al., 2010). In particular, the needs of women who choose to feed artificial milk should be met in a non-judgemental way (Lakshman et al., 2009). A small qualitative study in the UK found that artificial milk-feeding women felt pressured by staff (Wirihana and Barnard, 2012). Similar pressure experienced by women in another UK study resulted in them feeling that their care was 'breast-feeding centred', not 'woman centred' (Hoddinott and Pill, 2000), an unhelpful impression that should be avoided.

\section{Limitations}

This was a small qualitative study and as such is not generalisable. However, the fact that the findings are so comparable to other similar studies in other countries implies that one can apply findings from this body of work to other areas, when appropriate.

\section{Implications for practice and conclusion}

Promotion of breast feeding must take account of the complex contexts in which women make decisions and the timing of those decisions. Advice regarding breast feeding should take account of women's feelings and avoid undue pressure, while still promoting the benefits of breast feeding to women and their families. It may take many years of constant encouragement to raise the breastfeeding initiation rate to a level where breast feeding becomes viewed as a cultural norm in Ireland.

\section{Conflict of interest}

The authors declared no conflicts of interest with respect to the authorship and/or publication of this article.

\section{Acknowledgements and funding}

We are grateful to the women who agreed to participate in this study, and the staff who assisted and supported the study.

The National Infant Feeding Study, of which this small study forms a part, was commissioned by the Health Service Executive. The HSE had no role in study design, data collection, analysis, interpretation or report-writing or in the decision to submit the article for publication. The researchers are entirely independent from the funders.

\section{References}

Amir, L.H., Donath, S.M., 2008. Socioeconomic status and rates of breastfeeding in Australia: evidence from three national health surveys. Med. J. Aust. 189, 254-256.

Avishai, O., 2007. Managing the lactating body: the breast-feeding project and privileged motherhood. Qual. Sociol. 30, 135-152.

Bailey, C., Pain, R.H., Aarvold, J.E., 2004. A 'give it a go' breast-feeding culture and early cessation among low-income mothers. Midwifery 20, 240-250.

Beral, V., Bull, D., Doll, R., Peto, R., Reeves, G., 2002. Collaborative Group on Hormonal Factors in Breast Cancer. Breast cancer and breastfeeding: collaborative reanalysis of individual data from 47 epidemiological studies in 30 countries, including 50,302 women with breast cancer and 96,973 women without the disease. Lancet 360, 187-195.

Blyth, R., Creedy, D.K., Dennis, C.L., Moyle, W., Pratt, J., De Vries, S.M., 2002. Effect of maternal confidence on breastfeeding duration: an application of breastfeeding selfefficacy theory. Birth 29, 278-284.
Brown, A., Raynor, P., Lee, M., 2011. Healthcare professionals' and mothers' perceptions of factors that influence decisions to breastfeed or formula feed infants: a comparative study. J. Adv. Nurs. 67, 1993-2003.

Cattaneo, A., Yngve, A., Koletzko, B., Guzman, L.R., 2005. Protection, promotion and support of breast-feeding in Europe: current situation. Public Health Nutr. 8, $39-46$.

Central Statistics Office (CSO), Census 2006, Volume 8 - Occupations, 2007, Stationary Office, Dublin.

Cummings, R., Klineberg, R., 1993. Breastfeeding and other reproductive factors and the risk of hip fractures in elderly women. Int. J. Epidemiol. 22, 684-691.

Department of Health and Children (DoH\&C), 2005. Breastfeeding in Ireland: A Five Year Strategic Action Plan Department of Health and Children. The Stationary Office, Dublin.

Dewey, K., Heinig, M., Nommsen-Rivers L., 1995. Differences in morbidity between breastfed and formula-fed infants. J. Pediatr. 126, 696-702.

Dubois, L., Girard, M., 2003. Social determinants of initiation, duration and exclusivity of breastfeeding at the population level. Can. J. Public Health 94 300-305.

Dyson, L., McCormick F., Renfrew M.J., 2005. Interventions for promoting the initiation of breastfeeding. Cochrane Database of Systematic Reviews. Issue 2. Art. No: CD001688. http://dx.doi.org/10.1002/14651858.pub2.

Earle, S., 2000. Why some women do not breast feed: bottle feeding and fathers role. Midwifery 16, 323-330.

Enger, S., Ross, R., Henderson, B., Bernstein, L., 1997. Breastfeeding history pregnancy experience and risk of breast cancer. Br. J. Cancer 76, 118-123.

Economic and Social Research Institute (ESRI), 2013. Perinatal Statistics Report 2012. The Economic and Social Research Institute, Dublin.

Fewtrell, M.S., 2004. The long-term benefits of having been breast-fed. Curr Paediatr. 14, 97-103.

Fitzpatrick, C.C., Fitzpatrick, P.E., Darling, M.R.N., 1994. Factors associated with the decision to breastfeed among Irish women. Ir. Med. J. 87, 145-146.

Forster, D., McLachlan, H.L., 2010. Women's views and experiences of breastfeeding: positive, negative or just good for the baby? Midwifery 26, 116-125.

Freeman, V., 1996. A Longtitudinal Study of Growth, Feeding Practices and Iron Status in Healthy Children from Birth to Two Years of Age (Ph.D. thesis). Trinity College Dublin, Dublin.

Greally, T., 1997. Breastfeeding in the Mid-west. Mid Western Health Board, Limerick

Greene, J., Stewart-Knox, B., Wright, M., 2003. Feeding preferences and attitudes to breastfeeding and its promotion among teenagers in Northern Ireland. J. Hum. Lactation 19, 57-65.

Griffiths, L.J., Tate, A.R., Dezateux, C., 2005. The contribution of parental and community ethnicity to breastfeeding practices:evidence from the Millennium Cohort Study. International. J. Epidemiol. 34, 1378-1386.

Gudnadottir, M. Gunnarsson, B.S., Thorsdottir, I., 2006. Effects of sociodemographic factors on adherence to breastfeeding and other important infant dietary recommendations. Acta Paediatr. 95, 419-424.

Harder, T., Bergmann, R., Kallischnigg, G., Plagemann, A., 2005. Duration of breastfeeding and risk of overweight. Am. J. Epidemiol. 162, 397-403.

Hoddinott, P., Pill, R., 1999. Qualitative study of decisions about infant feeding among women in east end of London. Br. Med. J. 318, 30-34.

Hoddinott, P., Pill, R., 2000. A qualitative study of women's views about how health professionals communicate about infant feeding. Health Expect 3, 224-233.

Janke, J.R., 1994. Development of the breast-feeding attrition prediction tool. Nurs Res. 43, 100-104.

Khoury, A.J., Moazzem, S.W., Jarjoura, C.M., Carothers, C., Hinton, A., 2005 Breastfeeding initiation In low income women: role of attitudes, support and perceived control. Women's Health Issues 15, 64-72.

Lakshman, R., Ogilvie, D., Ong, K.K., 2009. Mothers' experiences of bottle-feeding: a systematic review of qualitative and quantitative studies. Arch. Dis. Child. 94 596-601.

Lucas, A., Cole, T.J., 1990. Breast milk and neonatal necrotising enterocolitis. Lancet 336, 1519-1523.

Lucas, A., Morley, R., Cole, T.J., 1998. Randomised trial of early diet in preterm babies and later intelligence quotient. Br. Med. J. 317, 1481-1487.

McAndrew, F., Thompson, J., Fellows, L., Large, A. Speed, M. Renfrew, M.J., 2012 Infant Feeding Survey 2010. The Information Centre for Health and Social Care 〈http://www.esds.ac.uk/doc/7281/mrdoc/pdf/7281_ifs-uk-2010_report.pdf

McDermott, M., O'Neill, C., 2000. Infant Feeding Survey. North Western Health Board, Sligo.

McFadden, A., Toole, G., 2006. Exploring women's views of breastfeeding: a focus group study within an area with high levels of socio-economic deprivation. Matern. Child Nutr. 2, 156-168.

McInnes, R.J., Chambers, J.A., 2008. Supporting breastfeeding mothers: qualitative synthesis. J. Adv. Nurs. 62, 407-427.

McSweeney, M., Kevany, J., 1982. Infant Feeding Practices in Ireland. Trinity College Dublin, Dublin.

Mitchell-Box, K., Braun, K.L., 2012. Fathers' thoughts on breastfeeding and implications for a theory-based intervention. J. Obstet. Gynecol. Neonatal Nurs. 41, E41-E50. http://dx.doi.org/10.1111/j.1552-6909.2012.01399.x.

Murphy, E., 1999. 'Breast is best': infant feeding decisions and maternal deviance. Sociol. Health Illn. 21, 187-208.

Nelson, A.M., 2012. A meta-synthesis related to infant feeding decision making. Am. J. Matern. Child Nurs. 37, 247-252.

Oakley., L.L., Renfrew, M.J., Kurinczuk, J.J., Quigley, M.A., 2013. Factors associated with breastfeeding in England: an analysis by primary care trust. BMJ Open 3 , e002765. http://dx.doi.org/10.1136/bmjopen-2013-002765. 
Owen, C.G., Martin, R.M., Whincup, P.H., Davey Smith, G., Cook, D.G., 2006. Does breastfeeding influence risk of type 2 diabetes in later life? A quantitative analysis of published evidence. Am. J. Clin. Nutr. 84, 1043-1054.

Present Authors, 2010. The National Infant Feeding Survey 2008. School of Nursing and Midwifery, Trinity College Dublin.

Rosenblatt, K.A., Thomas, D.B., 1993. WHO collaborative study of neoplasia and steroid contraceptives. Lactation and the risk of epithelial ovarian cancer. Int. J. Epidemiol. 22, 192-197.

Ryan, K., Bissell, P., Alexander, J., 2010. Moral work in women's narratives of breastfeeding. Soc. Sci. Med. 70, 951-958.

Singhal, A., Cole, T.J., Lucas, A., 2001. Early nutrition in preterm infants and later blood pressure: two cohorts after randomised trials. Lancet 357, 413-419.

Stewart-Knox, B., Gardiner, K., Wright, M., 2003. What is the problem with breastfeeding? A qualitative analysis of infant feeding perceptions. J. Hum. Nutr. Diet. 16, 265-273.
Tarrant, R., 2008. An Investigation of the Diets of Infants Born in Ireland During the First Six Months of Life (Ph.D. thesis). School of Biological Sciences, Dublin Institute of Technology, Dublin.

Tarrant, R.C., Sheridan-Pereira, M., McCarthy, R.A., Younger, K.M, Kearney, J.M., 2013. Mothers who formula feed: their practices, support needs and factors influencing their infant feeding decision. Child Care Pract. 19, 78-94.

Virtanen, S.M., Rasanen, L., Aro, A., Lindstrom, J., Sippola, H., Lounamaa, R., 1991. Infant feeding in Finnish children less than 7 yr of age with newly diagnosed IDDM. Childhood diabetes in Finland study group. Diabetes Care 14, 415-417.

Vohr, B.R., Poindexter, B.B., Dusick, A.M., et al., 2006. Beneficial effects of breast milk in the neonatal intensive care unit on the developmental outcome of extremely low birth weight infants at 18 months of age. Pediatrics 118 $115-123$.

Wirihana, L.A., Barnard, A., 2012. Women's perceptions of their healthcare experience when they choose not to breastfeed. Women Birth 25, 135-141. 